Decision Making in Manufacturing and Services

VOL. $13 \bullet 2019 \bullet$ No. 1-2 • PP. 17-35

\title{
A MILP Model for the Municipal Solid Waste Selective Collection Routing Problem
}

\author{
Antoni Korcyl*, Roger Książek*, Katarzyna Gdowska*
}

\begin{abstract}
Nowadays, selective solid waste management in the European Union belongs to important responsibilities of municipalities. In Solid Waste Management (SWM) the main operational task is to set a schedule for solid waste collection and to find optimal routes for garbage trucks, so that the total costs of the solid waste collection service can be minimized, subject to a series of constraints which not only guarantee the fulfillment of the SWM's obligations but also ensure the desirable quality level of that service. The optimization in garbage truck routing belongs to so called rich Vehicle Routing Problems as it aims to cover the following constraints: pickup nodes (clients) must be visited during their predefined time windows; the number and capacity of depots and specialized sorting units cannot be exceeded; each garbage truck can be assigned to at most one depot; each route should be dedicated to collecting one type of segregated solid waste, and the route must be served by a garbage truck which can collect that type of solid waste; the availability of garbage trucks and their drivers must be respected; each garbage truck must be drained at a specialized sorting unit before going back to the depot. This paper contributes a newly developed Mixed-Integer Programming (MIP) model for the Municipal Solid Waste Selective Collection Routing Problem (MSWSCRP) with time windows, limited heterogeneous fleet, and different types of segregated solid waste to be collected separately. Results obtained for solving small-sized instance of the MSWSCRP are reported.
\end{abstract}

Keywords: municipal solid waste collection system, solid waste segregated collection, MILP, rich VRP, Solid Waste Management

Mathematics Subject Classification: 90B06, 05C21, 68R05

Submitted: October 18, 2019

Revised: December 22, 2019

(C) 2019 Authors. This is an open access publication, which can be used, distributed and reproduced in any medium according to the Creative Commons CC-BY 4.0 License. License requiring that the original work has been properly cited.

\section{INTRODUCTION}

Nowadays, municipal solid waste selective collection is a crucial issue in Solid Waste Management (SWM) in the European Union, because Member States should ensure the

\footnotetext{
* AGH University of Science and Technology, Faculty of Management, Krakow, Poland, e-mail: akorcyl@zarz.agh.edu.pl, rksiazek@zarz.agh.edu.pl, kgdowska@zarz.agh.edu.pl
} 
separate collection of bio-waste by 2025 in order to minimize contamination of recyclable waste materials and ensure the optimal recycling of organic waste materials (European Parliament and European Council, 2019). Selective solid waste management is receiving increasing attention due to its impact on the public concern for the environment, as it helps to increase the amount of solid waste to be recycled and reduce the amount of solid waste sent to landfills (de Oliveira Simonetto and Borenstein, 2007).

In Poland, SWM is an obligation of municipal authorities whose responsibility it is to organize a system for collecting, segregating, treating and disposing municipal solid waste. This paper is devoted to an issue included in Solid Waste Management municipal solid waste selective collection. Municipal solid waste management is considered as an increasingly complex task which needs an enormous amount of resources and has a major environmental impact. At the managerial level, such a system aims at allocating garbage trucks to segregated municipal solid waste, and at determining their routes and daily amounts of segregated municipal solid waste to be sent to each specialized sorting unit or landfill, so that the total costs of service can be minimized while the desirable quality level of the service can be guaranteed. Computerized systems based on Operations Research techniques are developed to support decision makers in achieving remarkable cost savings as well as to improve municipal solid waste recovery (Ghiani et al., 2014).

In this paper, we present a Mixed-Integer Programming model (MIP) for the Municipal Solid Waste Selective Collection Routing Problem (MSWSCRP) with time windows, a limited heterogeneous fleet, and different types of municipal solid waste to be collected separately. The MSWSCRP is based on previous works (Korcyl et al., $2015,2016)$. The newly developed model enables the user to find optimal routes in a network containing a specific number of clients (pickup nodes). The routes are assigned to the fleet; at least one route can be assigned to each garbage truck, but not every vehicle must be assigned to any route. The optimal solution guarantees that all the clients are served in their predefined time windows. In result, the total number of garbage trucks used and the total length of routes are minimized, while ensuring the maximum number of properly served clients.

The remainder of the paper is organized as follows. Section 2 provides a short literature review on Solid Waste Management and the Vehicle Routing Problem (VRP) for the SWM. The newly developed MIP model for the Municipal Solid Waste Selective Collection Routing Problem (MSWSCRP) is presented in Section 3. Utilization of the newly developed model is illustrated with an example in Section 4 . The paper concludes with Section 5.

\section{STATE OF THE ART}

\subsection{Municipal Solid Waste Management}

Solid Waste Management all over the world is considered to be a major challenge to civil bodies. Municipal solid waste should be considered as an alternative source of energy since, if managed properly, biodegradable solid waste provides bio-diesel, fuel 
ethanol and liquid manure. Composting, bio-gas and inert waste recycle are currently available modes of solid waste treatment (Soni et al., 2016).

Municipal solid waste collected from an individual household consists of all the solid waste produced by this household, including segregated solid waste to be collected separately. This definition neither includes end-of-life vehicles nor solid waste produced by any other waste producers, even if that solid waste is not hazardous and its nature and composition is similar to the typical solid waste generated by a household.

In terms of municipal solid waste generation per capita in Europe in 2017, the lowest quantity was recorded in Poland $-311 \mathrm{~kg}$, whereas the average per capita solid waste generation in the EU equaled $483 \mathrm{~kg}$. At the top of the list were the biggest welfare countries, such as Denmark $(777 \mathrm{~kg})$, Germany $(627 \mathrm{~kg})$, and Luxembourg $(614 \mathrm{~kg})$. Solid waste generation per capita in European countries outside the EU was similar to the EU leaders - Norway $(724 \mathrm{~kg})$, Switzerland $(720 \mathrm{~kg})$, and Iceland $(656 \mathrm{~kg})$. In countries commonly considered tourist destinations, the figure was much higher than in Poland (e.g. Cyprus - $649 \mathrm{~kg}$ or Malta - $621 \mathrm{~kg}$ ), since tourists contributed significantly to solid waste production (Główny Urząd Statystyczny, 2018).

In each country, the amount of solid waste differs between regions and depends not only on the number of inhabitants but also on solid waste management in individual households. For example, in rural municipalities in Eastern Poland in 2017, waste generation per capita totaled $50 \mathrm{~kg}$, because individual households were able to handle the treatment of some types of solid waste, mostly biodegradable waste (which are collected by garbage trucks in other municipalities). In contrast, in municipalities known as tourist resorts, solid waste generation per capita was 1,000 kg (Główny Urząd Statystyczny, 2018).

In $2017,29 \%$ of collected solid waste in the EU was recycled, $27 \%$ was thermally rendered, 26\% was landfilled, and 16\% was composted (Główny Urząd Statystyczny, 2018). Solid waste treatment methods used in Poland in 2017 are presented in Table 1.

Table 1. Solid waste treatment methods used in Poland in 2017 (source: Główny Urząd Statystyczny, 2018)

\begin{tabular}{|l|c|c|}
\hline \multirow{2}{*}{ Disposal method } & \multicolumn{2}{|c|}{ Amount of solid waste disposed } \\
\cline { 2 - 3 } & [thousands of tonnes] & {$[\%]$} \\
\hline Recycling & 3199 & 27 \\
\hline Composting or fermenting & 848 & 7 \\
\hline Thermal rendering & 2922 & 24 \\
\hline Landfilling & 5000 & 42 \\
\hline Total & 11969 & 100 \\
\hline
\end{tabular}

Municipal solid waste selective collection requires the segregation of solid waste into several types with the same nature and properties, so that solid waste can be easier disposed or recycled. For the last 20 years in Poland, the amount of segregated municipal solid waste to be collected separately has been gradually growing. In 2012, ca. 1000 tons of segregated municipal solid waste was collected separately (ca. 10\% of 
the total municipal solid waste), and in 2017 it was over 3000 tons (27\%) (see Table 2). The objective of municipal solid waste selective collection is to recycle as much solid waste as possible. Ca. $10 \%$ of plastics and $22 \%$ of clothing and textiles collected separately was thermally rendered. Almost $100 \%$ of other types of solid waste were treated and recycled (see Table 3). The differences between municipalities in terms of the amounts of segregated solid waste collected separately depended on the different solid waste management systems adopted by the local authorities. In 2017, $90 \%$ of the total segregated municipal solid waste was collected separately in three municipalities, while in nine municipalities this ratio was below $1 \%$ of the total municipal solid waste (Główny Urząd Statystyczny, 2018).

Table 2. Segregated municipal solid waste collected separately in Poland in 2000-2017 (source: Główny Urząd Statystyczny, 2018)

\begin{tabular}{|l|c|c|}
\hline Year & $\begin{array}{c}\text { Amount } \\
{[\mathbf{t}]}\end{array}$ & $\begin{array}{c}\text { Increase over 2000 } \\
{[\%]}\end{array}$ \\
\hline 2000 & 1005.4 & 100.0 \\
\hline 2005 & 1275.0 & 126.8 \\
\hline 2010 & 2049.2 & 203.8 \\
\hline 2015 & 2537.4 & 252.4 \\
\hline 2016 & 2970.7 & 295.5 \\
\hline 2017 & 3239.4 & 322.2 \\
\hline
\end{tabular}

Table 3. The amount of segregated municipal solid waste collected separately and waste treatment in Poland in 2017 (source: Gtówny Urzad Statystyczny, 2018)

\begin{tabular}{|l|c|}
\hline Type of solid waste & $\begin{array}{c}\text { Rate of solid waste treatment } \\
{[\%]}\end{array}$ \\
\hline Metals & 99.9 \\
\hline Glass & 99.6 \\
\hline Paper and cardboard & 94.3 \\
\hline Plastics & 88.8 \\
\hline Clothing and textiles & 77.5 \\
\hline
\end{tabular}

In January 2018, the Regulation of the Minister of the Environment on detailed requirements for municipal solid waste transportation entered into force (Rozporzadzenie Ministra Środowiska..., 2016). This regulation specifies the requirements for solid waste transportation, means of transport, way of transport, and marking of garbage trucks. Now, two municipal solid waste selective collection systems are widely used: (1) municipal solid waste collection at source - solid waste is collected at waste producers'; this system is popular in cities, especially in single-family residential areas; and (2) municipal solid waste is collected at solid waste drop-off points - citizens need to bring their solid waste to a shared municipal solid waste drop-off point; this system works in cities in areas where multi-apartment residential buildings predominate (Bilitewski et al., 2000). 
In Solid Waste Management, the crucial issue is to choose the solid waste collection system properly, so that municipal solid waste collection can be performed according to schedule, be subject to legal regulations and with the lowest possible total costs. It is practically impossible to transport different types of waste with one vehicle, therefore planning and optimization is needed so that the objectives of municipal solid waste selective collection can be reached. When determining the number and types of garbage trucks to be used in the SWM system, the decision makers need to take into consideration the number of segregated municipal solid waste pickup points to be served and estimated amount of segregated solid waste to be collected from each of them.

\subsection{VRP for the Solid Waste Management}

The Vehicle Routing Problem (VRP) aims at determining the optimal set of routes to be served by a fleet, so that the total cost of used vehicles is minimized (Hanczar, 2010; Ambroziak and Jachimowski, 2011). For decades, the VRP has been used to solve various optimization problems in the field of transportation, logistics, and distribution management (Dantzig and Ramser, 1959; Laporte, 1992; Cordeau et al., 2007; Toth and Vigo, 2014). Studies on this NP-hard problem have resulted in several exact and heuristic techniques of general applicability (Crainic and Laporte, 1998; Cordeau et al., 2001; Liong et al., 2008; El-Sherbeny, 2010). By adding additional requirements, so-called rich VRPs were formulated, e.g. the Capacitated Vehicle Routing Problem with Time Windows (CVRPTW) (Sousa et al., 2011) in which capacity constraints and time windows were introduced and combined; the m-VRPTWT which is the Vehicle Routing Problem with Time Windows (VRPTW) formulated for a fleet of $m$ vehicles, where the objective is to determine at least $m$ routes to maximize the number of properly served clients and to minimize the total route length (Lau et al., 2003; Hoff et al., 2010; Shankar et al., 2014); the Periodic VRP (PVRP) consists of the creation of a sequence of routes for multiple days of a fixed planning period (Christofides and Beasley, 1984).

For a SWM system, the objective is to determine routes, i.e. subsets of nodes (municipal solid waste collection points or clients) to be served one by one in a sequence by a dedicated garbage truck of the fleet (see Das and Bhattacharyya, 2015). The garbage truck allocation to routes and the route optimization problem in a municipal multi-landfill solid waste selective collection system to which this paper is devoted is broadly considered as a rich VRP with heterogeneous fleet, time windows, multiple depots and other constraints (Ambroziak and Jachimowski, 2011; Korcyl et al., 2015, 2016). In Ghiani et al. (2014), optimization problems in SWM are surveyed in detail. Here we briefly review rich VRPs for municipal solid waste management to which we refer in the Municipal Solid Waste Selective Collection Routing Problem.

The VRPTW was the foundation for the Waste Collection Vehicle Routing Problem with Time Window (WCVRPTW) developed in Buhrkal et al. (2012) which aims at finding cost optimal routes for garbage trucks, so that all garbage bins can be emptied and solid waste can be delivered to landfills while respecting customer time windows and ensuring that drivers are given the breaks that the law requires. The WCVRPTW differs from the traditional VRPTW because the garbage trucks must visit landfills in order to empty their loads. 
Periodicity and repeatability are important issues in any municipal solid waste collection system as the solid waste collection trips need to be scheduled in advance, then announced to citizens, and finally executed accordingly to the plan. In Teixeira et al. (2004), the PVRP was developed for a SWM system, so that operation costs could be minimized by setting optimal solid waste collection routes for every day of the month, to be repeated every month.

The multi-depot VRP (m-VRP) was used in a formulation presented in the paper by de Oliveira Simonetto and Borenstein (2007) called the vehicle allocation and routing problem, where the objective of the formulation was to minimize the vehicle transportation costs involved. It also guaranteed that a given minimum percentage of waste load would be sent to each sorting unit.

In Xue et al. (2015) the capacitated VRP was used as the point of reference for an allocation problem aiming at determining the amount of waste to be sent from each pickup point to each landfill so that the overall transportation cost can be minimized. In the paper by Akhtar et al. (2017), the authors presented a modified Backtracking Search Algorithm (BSA) for capacitated VRP models with the smart bin concept to minimize the total waste collection route distance. Next, in Hannan et al. (2018), a newly-developed particle swarm optimization (PSO) algorithm for capacitated VRP models was presented which aimed at optimizing waste collection routes in terms of travel distance, total waste and waste collection efficiency. A sequential approach to capacitated VRP was presented in Vecchi et al. (2016), where the aim was to reduce the total distance traveled by garbage trucks.

The Fleet Size and Mix VRP was developed by Asefi et al. (2019b) to optimize the cost-effective integrated SWM system. This bi-objective model concurrently minimized the transportation cost in the entire SWM system, as well as total deviation from the fair load allocation to transfer stations. The problem included a heterogeneous fleet under multiple technologies and waste compatibility constraints. This research was continued in Asefi et al. (2019a), where a MILP model was developed to formulate the integrated SWM system in the framework of the Fleet Size and Mix Vehicle Routing Problem with Time Windows. A generalized VRP including multiple transfer stations, gather sites, heterogeneous fleet, and time windows for MSW collection was proposed in Son and Louati (2016). The multi-objective model aimed at maximizing the collected waste quantity and minimizing the environmental emissions. The model considered traveling in one-way routes, the number of vehicles per $\mathrm{m} 2$, and waiting time at traffic stops for the reduction of operational times.

In Koushik et al. (2019), the authors presented a multi-objective MILP model aimed at minimizing the total costs of a municipal Integrated SWM system, taking into account waste generation rates, composition, transportation modes, processing techniques, and revenues from waste processing. The model was to mirror the SWM system as closely as possible. This issue was also tackled in Yousefloo and Babazadeh (2020), where a multi-objective MILP model for SWM network design with the aim of optimizing total costs and risk objectives was developed. The first objective was to minimize overall economic costs and environmental costs (i.e. fixed costs including the initial cost for the establishment of waste treatment centers, waste transfer stations and recyclable solid waste collection centers; costs of transporting recyclable solid 
waste from waste generation sites to recyclable solid waste collection centers and transporting non-recyclable solid waste from generation sites to transfer stations; operational costs of solid waste treatment centers with different technologies, transfer stations and recyclable solid waste collection centers; environmental costs evaluated by considering the cost of emissions of dangerous gases during waste treatment and transportation; the revenue from sales of products produced at treatment centers and revenues from the sale of recyclable solid waste to recycling companies which was deducted from total costs), while the second objective aimed at minimizing the amount of risk function in the system, where the risk was related to the population of the residential area affected by solid waste treatment centers and the amount of emissions from solid waste processing in recyclable solid waste treatment centers. Also, Ayvaz-Cavdaroglu et al. (2019) used a multi-objective approach to minimize the total cost of selected periodical solid waste collection aimed at increasing the recovery rate for recyclable materials depending on the source and condition of the material. A multi-objective approach to modeling and solving the waste collection problem, providing efficient solutions in short computational times, is presented in Delgado-Antequera et al. (2020). The authors considered four different objectives to model the solid waste collection problem: minimizing the travel cost, balancing route length (i.e. minimizing the longest route), balancing route time balance (i.e. minimizing the difference between the duration of the longest and shortest routes), and minimizing the number of routes.

The potential utilization of artificial intelligence algorithms to solve the vehicle routing problem with time windows for a heterogeneous fleet of waste collection vehicles was investigated in Nowakowski et al. (2018). The authors developed an algorithm and a productive model of an online system enabling a comprehensive communication process for people requesting solid waste equipment for collection, the registering of data and solving the VRPTW with the objective of minimizing the number of garbage trucks used, assuring the timely collection of solid waste from a household, and minimizing the total collection cost. The system included parametric models of four algorithms (simulated annealing, tabu search, greedy, and bee colony optimization).

Numerous studies have been conducted on the practical aspects of using VRP-based methods for improving SWM in different municipalities, e.g. Rio de Janeiro, Brazil - Franca et al. (2019), Austin, Texas - Vu et al. (2020), Malaga, Spain - Ferrer and Alba (2019), Mashhad, Iran - Erfani et al. (2018), Krakow, Poland - Jakubiak (2016), La Palma, Spain - Expósito-Márquez et al. (2019), Ipoh City, Malaysia Malakahmad et al. (2014), Wageningen, the Netherlands - Bing et al. (2014), and many cities in Portugal - Ramos et al. (2018).

\section{MILP MODEL \\ FOR THE MUNICIPAL SOLID WASTE SELECTIVE COLLECTION ROUTING PROBLEM}

The Municipal Solid Waste Selective Collection Routing Problem (MSWSCRP) is a continuation of the research presented in Korcyl et al. (2015) and Korcyl et al. (2016) on the VRP in solid waste collection, but the MSWSCRP recognizes different types 
of solid waste, and assigns each garbage truck to at most one type of solid waste. Similarly to the problem defined in Korcyl et al. (2016), here we consider a municipal solid waste collection system with a heterogeneous fleet. The SWM system is served by more than one specialized sorting unit, and each of them belongs to predefined routes; at most one sorting unit may belong to each route. Garbage trucks have their home depots and for each depot a time window is defined, i.e. the earliest and the latest time of leaving the depot. Time windows are defined also for pickup nodes (clients), i.e. the earliest and the latest time to serve the client.

The MSWSCRP can be represented by a set of nodes $V$, where node 0 represents both the beginning and the end of each route. Set $R$ consists of selective solid waste pickup places, set $P$ represents sorting units, and set $W$ is the set of solid waste types. Set $C$ consists of garbage truck types, while $K$ is the set of all the garbage trucks belonging to the fleet; set $K$ is divided into subsets $K_{c}$ representing garbage trucks of type $c$.

The following notation is used:

\section{Variables}

$x_{i j k w}-1$ if garbage truck $k$ collects solid waste $w$ and traverses arc $(i, j), 0$ otherwise;

$y_{k w}-1$ if garbage truck $k$ collects solid waste $w$, 0 otherwise;

$a_{i k}$ - arrival time of garbage truck $k$ to node $i$

$u_{i k}$ - dwell time of garbage truck $k$ in node $i$;

\section{Parameters}

$d_{i w}$ - the amount of solid waste $w$ to be collected from node $i$;

$e_{i w}$ - the earliest time of picking up solid waste $w$ from node $i$;

$l_{i w}$ - the latest time of picking up solid waste $w$ from node $i$;

$s_{i w}$ - the amount of time needed for picking up solid waste $w$ from node $i$;

$E_{w}$ - the earliest time to leave a depot to collect solid waste $w$;

$L_{w}$ - the latest time to leave a depot to collect solid waste $w$;

$p_{c}$ - the latest time for garbage truck $c$ to get back to its home depot;

$q_{c}$ - capacity of garbage truck $c$;

$\alpha_{c}$ - the fixed cost of using garbage truck $c$;

$\beta_{c}$ - the variable cost of using garbage truck $c$;

$\delta_{c}$ - the cost of additional dwell time of garbage truck $c$;

$t_{i j}$ - time of traversing arc $(i, j)$;

$f_{i j k}-1$ if garbage truck $k$ is allowed to traverse arc $(i, j), 0$ otherwise;

$h_{k w}-1$ if garbage truck $k$ can collect solid waste $w, 0$ otherwise;

$\gamma_{1}$ - coefficient of the fixed cost of using a garbage truck;

$\gamma_{2}$ - coefficient of the variable cost of using a garbage truck;

$\gamma_{3}$ - coefficient of the cost of extra dwelling;

$M$ - large positive constant. 
The associated Mixed Integer Program is written as:

$$
\begin{aligned}
& \text { maximize } z=\sum_{k \in K} \sum_{w \in W}\left(1-y_{k w}\right)+\sum_{i \in V} \sum_{j \in V} \sum_{k \in K} \sum_{w \in W} x_{i j k w}+ \\
& -\gamma_{1} \sum_{c \in C} \sum_{k \in K_{c}} \sum_{j \in V /\{0\}} \sum_{w \in W} \alpha_{c} x_{0 j k w}+ \\
& -\gamma_{2} \sum_{c \in C} \sum_{k \in K_{c}} \sum_{i \in V /\{0\}} \sum_{j \in V /\{0\}} \sum_{w \in W} \beta x_{i j k w}+ \\
& -\gamma_{3} \sum_{c \in C} \sum_{k \in K_{c}} \sum_{i \in V /\{0\}} \delta_{c} u_{i k} \\
& \sum_{j \in V} \sum_{k \in K} x_{i j k w} \leqslant 1, i \in V /\{0\}, w \in W, i \neq j \\
& \sum_{j \in V /\{0\}} x_{0 j k w}=y_{k w}, k \in K, w \in W \\
& \sum_{i \in P} x_{i 0 k w}=y_{k w}, k \in K, w \in W \\
& \sum_{i \in V, i \neq j} x_{i j k w}=\sum_{i \in V, i \neq j} x_{j i k w}, j \in V, k \in K, w \in W \\
& x_{i j k w}+x_{j i k w} \leqslant 1, i \in V /\{0\}, j \in V, k \in K, w \in W, i \neq j \\
& x_{i i k w}=0, i \in V, k \in K, w \in W \\
& \sum_{i \in V /\{0\}} \sum_{j \in V /\{0\}} x_{i j k w} \leqslant M y_{k w}, k \in K, w \in W, i \neq j \\
& \sum_{i \in V /\{0\}} \sum_{i \in V} d_{i w} x_{i j k w} \leqslant q_{c}, c \in C, k \in K_{c}, w \in W \\
& a_{i k}+u_{i k}+\sum_{w \in W} s_{i w} y_{k w}+t_{i j}-a_{j k} \leqslant M\left(1-\sum_{w \in W} x_{i j k w}\right), \\
& i \in V, j \in V /\{0\}, k \in K, i \neq j \\
& a_{j k}-u_{i k}-\sum_{w \in W} s_{i w} y_{k w}-t_{i j}-a_{i k} \leqslant M\left(1-\sum_{w \in W} x_{i j k w}\right), \\
& i \in V, j \in V /\{0\}, k \in K, i \neq j \\
& \sum_{w \in W} e_{i w} \sum_{j \in V, i \neq j} x_{i j k w} \leqslant a_{i k}+u_{i k}, i \in V /\{0\}, k \in K
\end{aligned}
$$




$$
\begin{aligned}
& a_{i k}+u_{i k} \leqslant \sum_{w \in W} l_{i w} \sum_{j \in V, i \neq j} x_{i j k w}, i \in V /\{0\}, k \in K \\
& E_{w}-a_{0 k}-u_{0 k} \leqslant M\left(1-y_{k w}\right), k \in K, w \in W \\
& a_{0 k}+u_{0 k}-L_{w} \leqslant M\left(1-y_{k w}\right), k \in K, w \in W \\
& a_{i k}+u_{i k}+\sum_{w \in W} s_{i w} y_{k w} \leqslant p_{c} c \in C, k \in K_{c}, i \in V /\{0\} \\
& \sum_{i \in V, j \in P, i \neq j} x_{i j k w}+\sum_{i \in V, j \in P, i \neq j} x_{j i k w}=2 \cdot y_{k w}, k \in K, w \in W \\
& \sum_{i \in R, j \in P} x_{i j k w} \geqslant y_{k w} k \in K, w \in W \\
& \sum_{w \in W} y_{k w} \leqslant 1 k \in K \\
& x_{i j k w} \leqslant f_{i j k} i, j \in V /\{0\}, k \in K, w \in W, i \neq j \\
& y_{k w} \leqslant h_{k w} k \in K, w \in W \\
& a_{0 k}=0 k \in K \\
& a_{i k} \geqslant 0 k \in K, i \in V \\
& u_{i k} \geqslant 0 k \in K, i \in V \\
& x_{i j k w} \in\{0,1\} i, j \in V, k \in K, w \in W \\
& y_{k w} \in\{0,1\} k \in K, w \in W
\end{aligned}
$$

The objective function (1a) aims mainly at minimizing the total cost that consist of three types of costs: fixed cost incurred when a garbage truck departure on a solid waste collecting trip, variable cost of using garbage trucks (this cost is proportional to the duration of a solid waste collecting trip), and the cost of extra dwelling (incurred when it is necessary for a garbage truck to wait until the beginning of the time window of a pickup point).

To make the model work mirror the MSWSCRP properly, we introduced into the objective function two dimensionless summands aiming at minimizing the number of routes and maximizing the number of properly served pickup points. These two 
summands can be considered identical in terms of achieved improvement of the solution, e.g. when we decide to add another route serving 5 pickup points, the value of the objective function increases by $-1+5=4$ and it worse solution than adding a route serving 10 pickup points and leading to the increase of the objective function by $-1+10=9$. Moreover, when we decide to add two routes serving 5 pickup points each, the value of the objective function increases by $-2+2 \cdot 5=8$, what is still worse than one route serving 10 pickup points, etc.

With such an objective function it is crucial to choose proper values of coefficients $\gamma_{1}, \gamma_{2}$, and $\gamma_{3}$, which regulate two things in the objective function. Firstly, they reduce the values of costs to dimensionless quantity, and this is pretty obvious. Secondly, they enable to minimize costs and to maximize the value of the objective function at the same time, therefore their value must be chosen carefully, so that the computed value of total cost must always be less than the total value of the objective function that would be calculated directly with the reference to the scheduled routes.

Constraint (1b) ensures that every pickup node is served only once by a garbage truck collecting solid waste $w$. Constraints (1c) and (1d) guarantee that garbage truck $k$ collects solid waste $w$, while constraint (1s) ensures that each garbage truck is assigned to at most one type of solid waste. Moreover, constraints (1c) and (1d) ensure that if garbage truck $k$ is used it must leave its home depot and go back there. Waste collection routes are defined with constraints (1e), (1f), and (1g); each route begins and ends at the depot and consists of a sequence of pickup nodes. Thanks to constraint (1e) exactly one garbage truck assigned to solid waste $w$ is allowed to traverse arc $(i, j)$. Constraint $(1 \mathrm{~h})$ guarantee that arc $(i, j)$ can be served by garbage truck $k$ only if garbage truck $k$ was selected to be used in the system. Constraint (1i) ensures that capacity of garbage truck $k$ cannot be exceeded. Garbage truck flow balance equations $(1 \mathrm{j})$ and $(1 \mathrm{k})$ determine arrival time of garbage truck $k$ at pickup node $i$. Constraints (1l) and (1m) ensure that time windows defined for pickup node $i$ and solid waste $w$ is not exceeded, while constraints (1n) and (1o) guarantee that garbage truck $k$ leaves its home depot and comes back during the time window when picking up solid waste $w$ is allowed. Constraint (1p) ensures that every garbage truck assigned to solid waste $w$ comes back to its home depot before the end of working hours. Thanks to constraint (1q) if garbage truck $k$ enters pickup node $i$ it must also leave the node. Moreover, this constraint let exactly one garbage truck assigned to solid waste $w$ visit pickup node $i$; in other words, solid waste $w$ may be collected by at least one truck. Constraint (1r) defines what type of solid waste $(w)$ is collected by garbage truck $k$ while serving a route determined by binary variables $x_{i j k w}$ for given $k$ and $w$. Constraint (1t) let garbage truck $k$ serve arc $(i, j)$ only if garbage truck $k$ is allowed to traverse that arc, while constraint (1u) let garbage truck $k$ collect solid waste $w$ only if garbage truck $k$ can handle that type of solid waste.

\section{COMPUTATIONAL EXPERIMENT}

Computational experiment were executed on a computer with an Intel Core i7 quad-core CPU, running at $2.5 \mathrm{GHz}$ in a Win10 OS, with $16 \mathrm{~GB}$ of RAM. The MIP model has been solved, using the general-purpose mixed-integer optimization solver Gurobi, version 7.0.2. 


\subsection{Exemplary instance}

Let's consider a municipal solid waste selective collection system where two types of segregated solid waste are picked-up separately (Bio and Seg) with a heterogeneous fleet consisting of two types of garbage trucks ( $S v$ and $L v$ ). At the waste collection company's disposal are two garbage trucks of type $S v$ and one truck of type $L v$.

The waste collection system serves a network consisting of five pickup nodes $\left\{N_{1}, N_{2}, N_{3}, N_{4}, N_{5}\right\}$, a depot $\left\{N_{0}\right\}$ and two specialized sorting units $\left\{L_{I}, L_{I I}\right\}$ (see Figure 1). From pickup nodes $\left\{N_{1}, \ldots, N_{5}\right\}$ solid waste of both types is collected. Using the method presented in Korcyl et al. (2016), we decomposed nodes representing sorting units $L_{I}$ and $L_{I I}$ into sets of apparent nodes (one for each truck $k$ ), so that the feasibility of the problem is ensured. Therefore, each sorting unit is substituted by a set of three nodes, respectively, $\left\{L_{0}, L_{1}, L_{2}\right\}$ and $\left\{L_{3}, L_{4}, L_{5}\right\}$, because the fleet consists of three trucks. If truck $k$ is used in the system it must visit one sorting unit, which means that the garbage truck visits in fact one of nodes $\left\{L_{0}, L_{1}, L_{2}, L_{3}, L_{4}, L_{5}\right\}$.

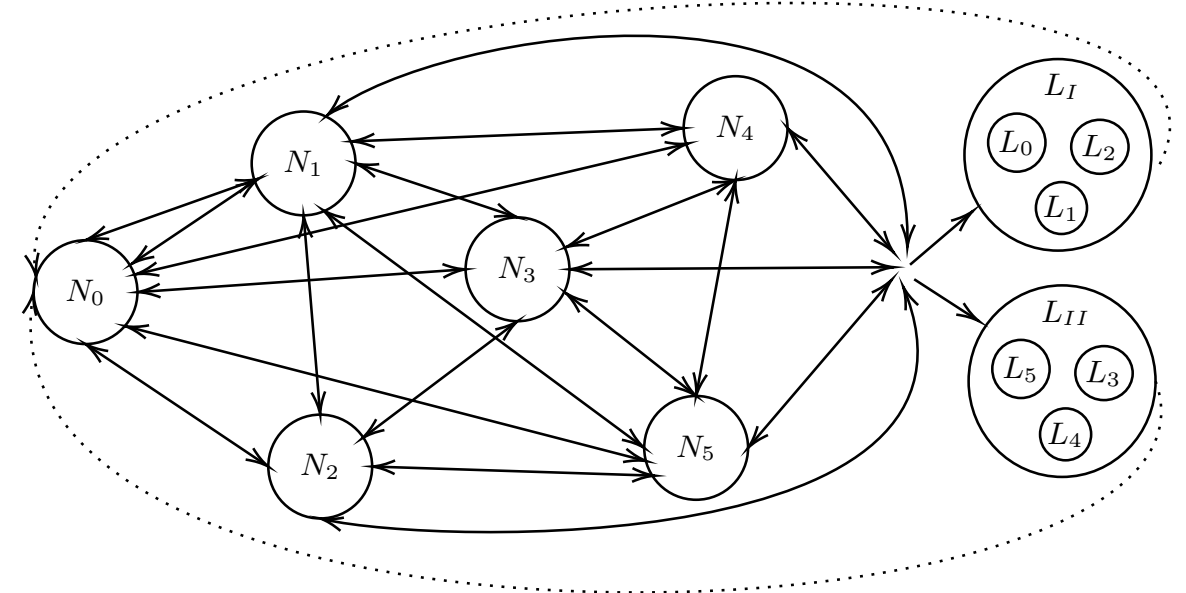

Fig. 1. Network served by the selective waste collection system

Demand $\left(d_{i w}\right)$ for collection service of solid waste $w$ in pickup node $i$ is presented in Table 4 . In Table 5 we present time windows $\left(e_{i w}, l_{i w}\right)$ for picking up solid waste $w$ from node $i$. Collection time of solid waste $w$ from pickup node $i\left(s_{i w}\right)$ and the time window for collecting solid waste $w\left(E_{w}, L_{w}\right)$ are presented in Table 6 . We assume that garbage truck $k$ can traverse any arc and collect any type of solid waste.

Times of traversing each arc $(i, j)$ are presented in Table 7 . Travel times between any pickup node and any node representing sorting unit are equal. Note, that there is no arc between nodes $\left\{L_{0}, L_{1}, L_{2}\right\}$.

In Table 8 we specify characteristic features of garbage truck of type $c$ : the latest time for coming back to the home depot $\left(p_{c}\right)$, capacity $\left(q_{c}\right)$, and costs of using a garbage truck of type $c$ : fixed cost $\left(\alpha_{c}\right)$, variable cost $\left(\beta_{c}\right)$ which depends on the length of the route, and the cost of extra dwelling $\left(\delta_{c}\right)$. Value of coefficients $\gamma_{1}, \gamma_{2}$, and $\gamma_{3}$ is 0.0001 . 
Table 4. Demand $\left(d_{i w}\right)$ for waste collection service of municipal solid waste $w$ in pickup node $i$

\begin{tabular}{|c|c|c|c|c|c|}
\cline { 2 - 6 } \multicolumn{1}{c|}{} & $N_{1}$ & $N_{2}$ & $N_{3}$ & $N_{4}$ & $N_{5}$ \\
\hline Bio & 1 & 6 & 1 & 5 & 1 \\
\hline Seg & 5 & 1 & 7 & 9 & 1 \\
\hline
\end{tabular}

Table 5. Time windows for picking up segregated solid waste $w$ from node $i$

\begin{tabular}{|c|c|c|c|c|c|c|c|c|c|c|}
\cline { 2 - 11 } \multicolumn{1}{c|}{} & \multicolumn{4}{c|}{ The earliest time $\left(e_{i w}\right)$} & \multicolumn{4}{c|}{ The latest time $\left(l_{i w}\right)$} \\
\cline { 2 - 11 } \multicolumn{1}{c|}{} & $N_{1}$ & $N_{2}$ & $N_{3}$ & $N_{4}$ & $N_{5}$ & $N_{1}$ & $N_{2}$ & $N_{3}$ & $N_{4}$ & $N_{5}$ \\
\hline Bio & 34 & 12 & 11 & 11 & 23 & 86 & 56 & 62 & 78 & 65 \\
\hline Seg & 28 & 29 & 10 & 15 & 31 & 89 & 99 & 78 & 66 & 72 \\
\hline
\end{tabular}

Table 6. Collection time of segregated solid waste $w$ from pickup node $i\left(s_{i w}\right)$ and the time window for collecting waste $w\left(E_{w}, L_{w}\right)$

\begin{tabular}{|c|c|c|c|c|c|c|c|}
\cline { 2 - 8 } \multicolumn{1}{c|}{} & \multicolumn{5}{c|}{ Collection time $\left(s_{i w}\right)$} & The earliest time & The latest time \\
\cline { 2 - 8 } \multicolumn{1}{c|}{} & $N_{1}$ & $N_{2}$ & $N_{3}$ & $N_{4}$ & $N_{5}$ & $E_{w}$ & $L_{w}$ \\
\hline Bio & 1 & 3 & 2 & 3 & 3 & 0 & 5 \\
\hline Seg & 2 & 3 & 1 & 2 & 1 & 0 & 5 \\
\hline
\end{tabular}

Table 7. Time of traversing arc $(i, j)\left(t_{i j}\right)$

\begin{tabular}{|l|c|c|c|c|c|c|c|c|}
\cline { 2 - 9 } \multicolumn{1}{c|}{} & $N_{0}$ & $N_{1}$ & $N_{2}$ & $N_{3}$ & $N_{4}$ & $N_{5}$ & $\left\{L_{0}, L_{1}, L_{2}\right\}$ & $\left\{L_{3}, L_{4}, L_{5}\right\}$ \\
\hline$N_{0}$ & 0 & 10 & 9 & 6 & 6 & 8 & 0 & 0 \\
\hline$N_{1}$ & 10 & 0 & 10 & 2 & 5 & 5 & 2 & 2 \\
\hline$N_{2}$ & 9 & 10 & 0 & 2 & 3 & 1 & 5 & 3 \\
\hline$N_{3}$ & 6 & 2 & 2 & 0 & 7 & 8 & 2 & 1 \\
\hline$N_{4}$ & 6 & 5 & 3 & 7 & 0 & 6 & 7 & 7 \\
\hline$N_{5}$ & 8 & 5 & 1 & 8 & 6 & 0 & 10 & 8 \\
\hline$\left\{L_{0}, L_{1}, L_{2}\right\}$ & 0 & 2 & 5 & 2 & 7 & 10 & 0 & 0 \\
\hline$\left\{L_{3}, L_{4}, L_{5}\right\}$ & 0 & 2 & 3 & 1 & 7 & 8 & 0 & 0 \\
\hline
\end{tabular}

Table 8. Characteristic features of garbage truck of type $c$

\begin{tabular}{|c|c|c|c|c|c|}
\cline { 2 - 6 } \multicolumn{1}{c|}{} & $p_{c}$ & $q_{c}$ & $\alpha_{c}$ & $\beta_{c}$ & $\delta_{c}$ \\
\hline$S v$ & 100 & 34 & 100 & 1 & 2 \\
\hline$L v$ & 100 & 48 & 100 & 1 & 2 \\
\hline
\end{tabular}

\subsection{Computational results}

As a solution for the instance described in Subsection 4.1 two garbage trucks of type $S v$ were used for collecting waste Bio, and one garbage truck of type $L v$ collected solid 
waste $\mathrm{Seg}$ from all the nodes (see Table 9). In Table 10 arrival times and extra dwell time at pickup nodes is presented. Note, that garbage truck $L v$ was the only one that had to dwell at pickup node $N_{1}$, because it arrived there before the time window for collecting solid waste $\mathrm{Seg}$.

In Figure 2 obtained schedule of segregated solid waste collection is presented; it includes time lines for garbage trucks and service schedule for pickup nodes.

Table 9. Garbage truck assignment to different types of segregated solid waste ( $\left.y_{k w}\right)$

\begin{tabular}{|c|c|c|c|}
\cline { 2 - 4 } \multicolumn{1}{c|}{} & $S v_{1}$ & $S v_{2}$ & $L v$ \\
\hline Bio & 1 & 1 & - \\
\hline Seg & - & - & 1 \\
\hline
\end{tabular}

Table 10. Arrival times $a_{i k}$ and extra dwell times $\left(u_{i k}\right)$ of garbage truck $k$ at pickup node $i$

\begin{tabular}{|l|c|c|c|c|c|c|c|c|c|c|c|c|}
\cline { 2 - 14 } \multicolumn{1}{c|}{} & $N_{0}$ & $N_{1}$ & $N_{2}$ & $N_{3}$ & $N_{4}$ & $N_{5}$ & $L_{0}$ & $L_{1}$ & $L_{2}$ & $L_{3}$ & $L_{4}$ & $L_{5}$ \\
\hline$S v_{1}$ & $0(5)$ & - & - & $11(0)$ & - & - & $15(0)$ & - & - & - & - & - \\
\hline$S v_{2}$ & $0(5)$ & $37(0)$ & $14(0)$ & - & $20(0)$ & $29(0)$ & - & - & - & $40(0)$ & - & - \\
\hline$L v$ & $0(5)$ & $26(2)$ & $37(0)$ & $11(0)$ & $19(0)$ & $35(0)$ & - & - & - & - & $43(0)$ & - \\
\hline
\end{tabular}

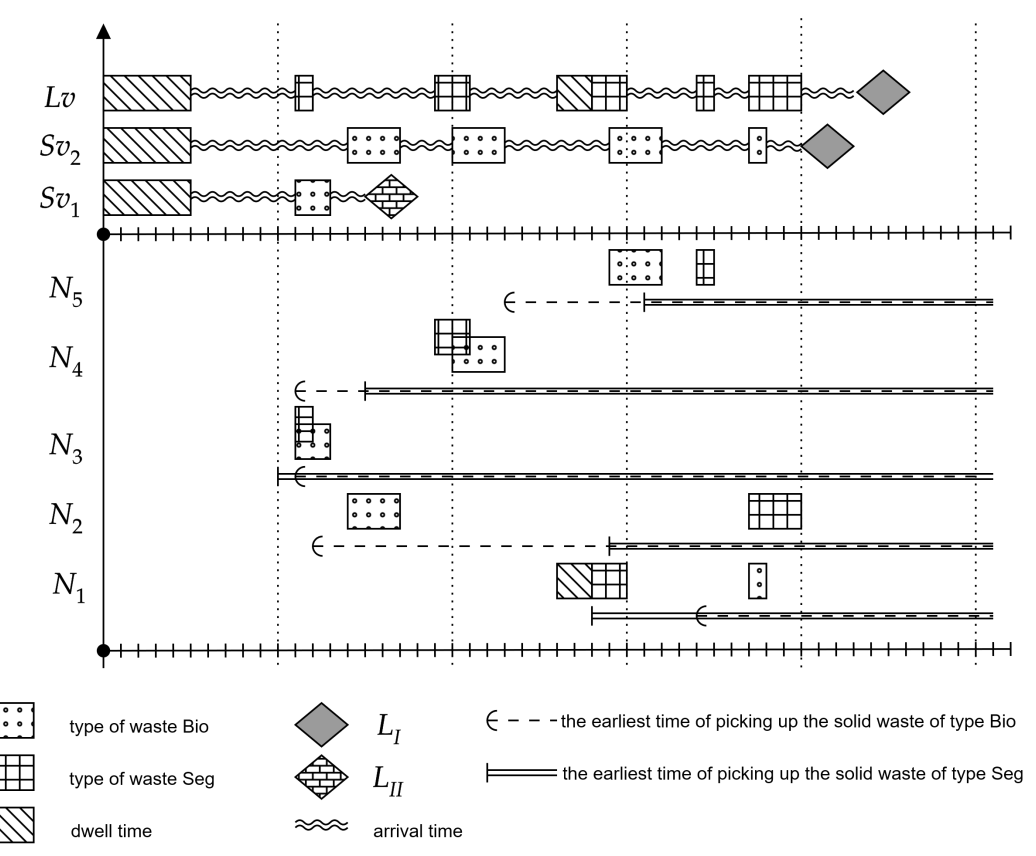

Fig. 2. Selected solid waste collection schedule 
Computation time was limited to 30 sec. Feasible solution was found and objective function value was 18.96 . Optimization $G A P$ was $0.0076 \%$; optimization $G A P$ is the difference between the value of the objective function computed for a given feasible solution and the best estimate of that value (see Formula (2)).

$$
G A P=\left(\frac{\mid \text { ObjBound }- \text { ObjVal } \mid}{|O b j V a l|}\right) 100 \%
$$

where:

ObjBound - the best estimate of the value of the objective function,

ObjVal - the value of the objective function computed for a given feasible solution.

\section{CONCLUSIONS}

The main contribution of this paper is the introduction of a newly developed MIP model for the VRP for the municipal solid waste selective collection system. The MSWSCRP allows the collection of solid waste of different types separately, subject to such constraints as time windows, and vehicle limitations.

This paper justified the need for new models for routing a solid waste collection fleet in a municipal solid waste selective collection system. Along with the rapidly escalating climate catastrophe, the positive social and environmental impact of municipal solid waste selective collection have been receiving increasing attention. A hot topic in Solid Waste Management and a natural direction for future research in this area is the pursuit of an answer to the following question: how to collect huge amounts of municipal segregated solid waste in the most efficient way.

As the model for the MSWSCRP presented in this paper has already been utilized for solving randomly generated instances, the future research should concentrate on testing the MSWSCRP with real instances to compare the quality of generated solutions with solid waste collection schedules utilized in practice. Another direction of future research is supplementing the problem with constraints so that it can mirror the real municipal SWM system as close as possible. It may also request the addition of other objectives to the objective function; dealing with a multi-objective optimization problem may make it necessary to use optimization methods dedicated to such problems.

\section{ACKNOWLEDGEMENTS}

This work was supported by the AGH University of Science and Technology with the grant for the maintenance of research potential. 


\section{REFERENCES}

Akhtar, M., Hannan M., Begum, R., Basri, H., Scavino, E., 2017. Backtracking search algorithm in CVRP models for efficient solid waste collection and route optimization. Waste Management, 61, pp. 117-128, doi: https://doi.org/10.1016/j.wasman.2017.01.022.

Ambroziak, T., Jachimowski, R., 2011. Wybrane aspekty zagadnienia okien czasowych w problemie trasowania pojazdów. Automatyka, 15(2), pp. 51-59.

Asefi, H., Shahparvari, S., Chhetri, P., 2019a. Integrated municipal solid waste management under uncertainty: A tri-echelon city logistics and transportation context. Sustainable Cities and Society, 50:101606, doi: https://doi.org/10.1016/j.scs.2019.101606.

Asefi, H., Shahparvari, S., Chhetri, P., Lim S., 2019b. Variable fleet size and mix VRP with fleet heterogeneity in integrated solid waste management. Journal of Cleaner Production, 230, pp.1376-1395, doi: https://doi.org/10.1016/j.jclepro.2019.04.250.

Ayvaz-Cavdaroglu, N., Coban, A., Firtina-Ertis, I., 2019. Municipal solid waste management via mathematical modeling: A case study in Istanbul, Turkey. Journal of Environmental Management, 244, pp. 362-369, doi: https://doi.org/10.1016/j.jenvman.2019.05.065.

Bilitewski, B., Marek, K., Härdtle, G., 2000. Abfallwirtschaft: Handbuch für Praxis und Lehre, dritte, neubearbeitete auflage edition. Springer, Berlin - Heidelberg.

Bing, X., de Keizer, M., Bloemhof-Ruwaard, J.M., van der Vorst, J.G., 2014. Vehicle routing for the eco-efficient collection of household plastic waste. Waste Management, 34(4), pp. 719-729, doi: https://doi.org/10.1016/j.wasman.2014.01.018.

Buhrkal, K., Larsen, A., Ropke, S., 2012. The waste collection vehicle routing problem with time windows in a city logistics context. Procedia - Social and Behavioral Sciences, 39, pp. 241-254, doi: https://doi.org/10.1016/j.sbspro.2012.03.105.

Christofides, N., Beasley, J.E., 1984. The period routing problem. Networks, 14(2), pp. 237-256, 1984, doi: https://doi.org/10.1002/net.3230140205.

Cordeau, J.-F., Laporte, G., Mercier, A., 2001. A unified tabu search heuristic for vehicle routing problems with time windows. Journal of the Operational Research Society, 52(8), pp. 928-936, doi: https://doi.org/10.1057/palgrave.jors.2601163.

Cordeau, J.-F., Laporte, G., Savelsbergh, M.W., Vigo, D., 2007. Vehicle routing. In: Transportation, volume 14 of Handbooks in Operations Research and Management Science, Elsevier, pp. 367-428, doi: https://doi.org/10.1016/S0927-0507(06)14006-2.

Crainic, T.G., Laporte, G., 1998. Fleet Management and Logistics. Springer US, Boston, MA, doi: https://doi.org/10.1007/978-1-4615-5755-5.

Dantzig, G.B., Ramser, J.H., 1959. The truck dispatching problem. Management Science, 6, pp. 80-91.

Das, S., Bhattacharyya, B.K., 2015. Optimization of municipal solid waste collection and transportation routes. Waste Management, 43, pp. 9-18, doi: https://doi.org/10.1016/ j.wasman.2015.06.033.

Delgado-Antequera, L., Caballero, R., Sánchez-Oro, J., Colmenar, J.M., Martí, R., 2020. Iterated greedy with variable neighborhood search for a multiobjective waste collection problem. Expert Systems with Applications, 145:113101, doi: https://doi.org/10.1016/ j.eswa.2019.113101.

El-Sherbeny, N.A., 2010. Vehicle routing with time windows: An overview of exact, heuristic and metaheuristic methods. Journal of King Saud University - Science, 22(3), pp. 123-131 doi: https://doi.org/10.1016/j.jksus.2010.03.002. 
Erfani, S.M.H., Danesh, S., Karrabi, S.M., Shad, R., Nemati, S., 2018. Using applied operations research and geographical information systems to evaluate effective factors in storage service of municipal solid waste management systems. Waste Management, 79, pp. 346-355, doi: https://doi.org/10.1016/j.wasman.2018.08.003.

European Parliament and European Council. Directive (EU) 2019/904 of the European Parliament and of the council of 5 June 2019 on the reduction of the impact of certain plastic products on the environment, $\mathrm{PE} / 11 / 2019 / \mathrm{REV} / 1$.

Expósito-Márquez, A., Expósito-Izquierdo, C., Brito-Santana, J., Moreno-Pérez, J.A., 2019. Greedy randomized adaptive search procedure to design waste collection routes in La Palma. Computers \& Industrial Engineering, 137:106047, doi: https://doi.org/10.1016/ j.cie.2019.106047.

Ferrer, J., Alba, E., 2019. BIN-CT: Urban waste collection based on predicting the container fill level. Biosystems, 186:103962, doi: https://doi.org/10.1016/j.biosystems.2019.04.006.

Franca, L.S., Ribeiro, G.M., de Lorena Diniz Chaves, G., 2019. The planning of selective collection in a real-life vehicle routing problem: A case in Rio de Janeiro. Sustainable Cities and Society, 47:101488, doi: https://doi.org/10.1016/j.scs.2019.101488.

Ghiani, G., Laganà, D., Manni, E., Musmanno, R., Vigo, D., 2014. Operations research in solid waste management: A survey of strategic and tactical issues. Computers \& Operations Research, 44, pp. 22-32, doi: https://doi.org/10.1016/j.cor.2013.10.006.

Główny Urząd Statystyczny [Statistics Poland]. Ochrona środowiska 2018 [Environment 2018]. Analizy statystyczne [Statistical Analyses], Główny Urząd Statystyczny [Statistics Poland], Warszawa 2018, https://stat.gov.pl/download/gfx/portalinformacyjny/pl/ defaultaktualnosci/5484/1/19/1/ochrona_srodowiska_2018.pdf.

Hanczar, P., 2010. Wspomaganie decyzji w obszarze wyznaczania tras pojazdów. Decyzje, 13, pp. $55-83$.

Hannan, M., Akhtar, M., Begum, R., Basri, H., Hussain, A., Scavino, E., 2018. Capacitated vehicle-routing problem model for scheduled solid waste collection and route optimization using PSO algorithm. Waste Management, 71, pp. 31-41, doi: https://doi.org/10.1016/ j.wasman.2017.10.019.

Hoff, A., Andersson, H., Christiansen, M., Hasle, G., Løkketangen, A., 2010. Industrial aspects and literature survey: Fleet composition and routing. Computers \& Operations Research, 37(12), pp. 2041-2061, doi: https://doi.org/10.1016/j.cor.2010.03.015.

Jakubiak, M., 2016. The improvement in collection of municipal waste on the example of a chosen municipality. Transportation Research Procedia, 16, pp. 122-129, doi: https: //doi.org/10.1016/j.trpro.2016.11.013.

Korcyl, A., Gdowska, K., Książek R., 2015. Optymalizacja tras odbioru odpadów komunalnych z wykorzystaniem różnych typów pojazdów i ograniczeniami czasowymi w obsłudze klienta. Logistyka, 4, pp. 9202-9211.

Korcyl, A., Książek, R., Gdowska, K., 2016. A MILP model for route optimization problem in a municipal multi-landfill waste collection system. In: Sawik, T. (ed.), ICIL 2016: 13th International Conference on Industrial Logistics. 28 September - 1 October, Zakopane, Poland. Conference Proceedings. AGH University of Science and Technology, International Center for Innovation and Industrial Logistics, Krakow, pp. 109-118.

Koushik, P., Subhasish, C., Amit, D., Akhouri, K., Subhabrata, R., 2019. A comprehensive optimization model for integrated solid waste management system: A case study. Environmental Engineering Research, 24(2), pp. 220-237, http://eeer.org/journal/view.php? number $=947$. 
Laporte, G., 1992. The travelling salesman problem: an overview of exact and approximate algorithms. European Journal of Operational Research, 59, pp. 231-247.

Lau, H.C., Sim, M., Teo, K.M., 2003. Vehicle routing problem with time windows anda limited number of vehicles. European Journal of Operational Research, 148(3), pp. 559-569, doi: https://doi.org/10.1016/S0377-2217(02)00363-6.

Liong, C.Y., Wan Rosmanira, I., Khairuddin, O., Mourad, Z., 2008. Vehicle routing problem: Models and solutions. Journal of Quality Measurement and Analysis, 4(1), pp. 205-218, http://www.ukm.my/jqma/jqma4_1a.html.

Malakahmad, A., Bakri, P.M., Mokhtar, M.R.M., Khalil, N., 2014. Solid waste collection routes optimization via GIS techniques in Ipoh City, Malaysia. Procedia Engineering, 77, pp. 20-27, doi: https://doi.org/10.1016/j.proeng.2014.07.023.

Nowakowski, P., Szwarc, K., Boryczka, U., 2018. Vehicle route planning in e-waste mobile collection on demand supported by artificial intelligence algorithms. Transportation Research Part D: Transport and Environment, 63, pp. 1-22, doi: https://doi.org/10. 1016/j.trd.2018.04.007.

Oliveira Simonetto, de, E., Borenstein, D., 2007. A decision support system for the operational planning of solid waste collection. Waste Management, 27(10), pp. 1286-1297, doi: https://doi.org/10.1016/j.wasman.2006.06.012.

Ramos, T.R.P., Morais, de, C.S., Barbosa-Póvoa, A.P., 2018. The smart waste collection routing problem: Alternative operational management approaches. Expert Systems with Applications, 103, pp. 146-158, doi: https://doi.org/10.1016/j.eswa.2018.03.001.

Rozporzadzenie Ministra Środowiska z dnia 7 października 2016 r. w sprawie szczegótowych wymagań dla transportu odpadów, Dz.U. 2016 poz. 1742.

Shankar, H., Mani, G., Pandey, K., 2014. GIS based solution of multi-depot capacitated vehicle routing problem with time window using tabu search algorithm. International Journal of Traffic and Transportation Engineering, 3(2), pp. 83-100, doi: https://doi. org/10.5923/j.ijtte.20140302.05.

Son, L.H., Louati, A., 2016. Modeling municipal solid waste collection: A generalized vehicle routing model with multiple transfer stations, gather sites and inhomogeneous vehicles in time windows. Waste Management, 52, pp. 34-49, doi: https://doi.org/10.1016/j.wasman. 2016.03.041.

Soni, A., Patil, D., Argade, K., 2016. Municipal solid waste management. Procedia Environmental Sciences, 35, pp. 119-126, doi: https://doi.org/10.1016/j.proenv.2016.07.057.

Sousa, J.C., Biswas, H.A., Brito, R., Silveira, A., 2011. A multi objective approach to solve capacitated vehicle routing problems with time windows using mixed integer linear programming. International Journal of Advanced Science and Technology, 28, pp. 1-8, http://www.sersc.org/journals/IJAST/vol28/1.pdf.

Teixeira, J., Antunes, A.P., Sousa, de, J.P., 2004. Recyclable waste collection planning - a case study. European Journal of Operational Research, 158(3), pp. 543-554, doi: https://doi.org/10.1016/s0377-2217(03)00379-5.

Toth P., Vigo, D., 2014. Vehicle Routing. Society for Industrial and Applied Mathematics, Philadelphia, PA, doi: https://doi.org/10.1137/1.9781611973594.fm.

Vecchi, T.P., Surco, D.F., Constantino, A.A., Steiner, M.T., Jorge, L.M., Ravagnani, M.A., Paraíso, P.R., 2016. A sequential approach for the optimization of truck routes for solid waste collection. Process Safety and Environmental Protection, 102, pp. 238-250, doi: https://doi.org/10.1016/j.psep.2016.03.014. 
Vu, H.L., Ng, K.T.W., Fallah, B., Richter, A., Kabir, G., 2020. Interactions of residential waste composition and collection truck compartment design on GIS route optimization. Waste Management, 102, pp. 613-623, https://doi.org/10.1016/j.wasman.2019.11.028.

Xue, W., Cao, K., Li, W., 2015. Municipal solid waste collection optimization in Singapore. Applied Geography, 62, pp. 182-190, doi: https://doi.org/10.1016/j.apgeog.2015.04.002.

Yousefloo, A., Babazadeh, R., 2020. Designing an integrated municipal solid waste management network: A case study. Journal of Cleaner Production, 244:118824, doi: https://doi.org/ $10.1016 /$ j.jclepro.2019.118824. 